\title{
The functional BPV-1 E2 trans-activating protein can act as a repressor by preventing formation of the initiation complex
}

\author{
Nathalie Dostatni, ${ }^{1}$ Paul F. Lambert, ${ }^{2,3}$ Rosemary Sousa, ${ }^{1}$ Jonathan Ham, ${ }^{1}$ Peter M. Howley, ${ }^{2}$ \\ and Moshe Yaniv ${ }^{1}$ \\ ${ }^{1}$ Unité des Virus Oncogènes, Département des Biotechnologies, UA 1149 du Centre National de la Recherche Scientifique, \\ Institut Pasteur, 75724 Paris, France; ${ }^{2}$ Laboratory of Tumor Virus Biology, National Cancer Institute, Bethesda, Maryland \\ 20892 USA
}

The products encoded by the E2 open reading frame of the papillomaviruses are DNA-binding transcription factors involved in the positive or negative regulation of multiple viral promoters. To further understand the mechanisms by which the same transcription factor may act differentially, the full-length BPV-1 E2 protein was expressed and purified from yeast and assayed in vitro for its capacity to modulate transcription. E2 stimulated transcription of the HSV thymidine kinase (TK) promoter when E2-binding sites were positioned in an enhancer configuration $\sim \mathbf{1 0 0}$ bp upstream of the promoter start site. In contrast, the same full-length E2 protein repressed transcription of the HPV-18 E6/E7 $P_{105}$ promoter. This repression was mediated through binding to the E2 DNA-binding site immediately upstream of the $P_{105}$ promoter TATA box and could be abrogated by preincubation of the HPV-18 $P_{105}$ promoter template with the nuclear extract allowing the formation of the preinitiation complex. In vitro DNA-binding experiments with purified E2 and TFIID showed that binding of E2 to its DNA target placed at different positions with respect to the TATA box differentially affects binding of TFIID to its cognate site. In these respects, $E 2$ is similar to the bacteriophage $\lambda$ repressor, which can act either as a repressor or an activator of transcription depending on the position of its binding sites relative to the promoter sequences.

[Key Words: In vitro transcription; activation; repression; DNA-binding interference; BPV-1 E2; TFIID]

Received January 28, 1991; revised version accepted June 20, 1991.

Studies of transcriptional control in eukaryotes have focused mainly on genetic elements that mediate positive regulation. Many positive regulatory elements and transcription factors have been identified that are selectively able to stimulate transcription of specific genes. In most cases, trans-activators bind directly to cis-acting sequences, localized either in the vicinity of the promoter or in a remote position, and transmit a positive signal to the transcription initiation complex. Although many components involved in this activation are known, the mechanisms underlying transcriptional stimulation remain unclear. The activating proteins that bind DNA directly are generally composed of at least two distinct domains: One is responsible for contact of the protein with the DNA and provides the specificity for the recognition of the target site; the second is involved in the

${ }^{3}$ Present address: McArdle Laboratory for Cancer Research, Department of Oncology, University of Wisconsin-Madison, Madison, Wisconsin 53706-1599 USA. activation itself (for review, see Mitchell and Tiian 1989; Struhl 1989). It has been proposed that the activation domain of these proteins might function by enhancing either the binding or activity of components of the transcription complex. Alternatively, the positive signal could be transmitted by interactions with cellular factors, which do not themselves bind DNA, but serve as adaptors connecting the transcription factor to the initiation complex (for review, see Lewin 1990; Ptashne and Gann 1990).

Repressors have emerged only recently as important factors in the transcriptional control of eukaryotic genes. The existence of positive as well as negative mechanisms to control transcription most likely allows a more selective transcriptional response to environmental and differentiation stimuli. Repression of transcription therefore appears to be an integral part of this transcriptional control and may be as important as activation in the regulation of eukaryotic promoters. Many steps of the trans-activation mechanism can be blocked or perturbed by repressor factors. This block can occur by com- 
petitive binding of the repressor with a crucial activator or by negative interference with its function /for review, see Levine and Manley 1989; Renkavitz 1990).

The products of the E2 open reading frame (ORF) of papillomaviruses constitute a family of DNA-binding transcriptional modulators sharing the capacity to be either activators or repressors of viral transcription (for review, see Dostatni et al. 1989; McBride et al. 1989b). The bovine papillomavirus type 1 (BPV-1) E2 protein is the one studied most extensively in this family of factors and was first described as a specific trans-activator of BPV-1 transcription (Spalholz et al. 1985). The E2 proteins are sequence-specific DNA-binding proteins (Androphy et al. 1987; Moskaluk and Bastia 1987). The carboxy-terminal 100-amino-acid conserved domain of $\mathrm{E} 2$ is responsible for dimerization and sequence-specific binding to a short palindromic DNA target, ACCN $_{6}$ GGT (Dostatni et al. 1988; Giri and Yaniv 1988; McBride et al. 1988; Moskaluk and Bastia 1988b; McBride et al. 1989a). The amino-terminal domain of E2, which is also highly conserved among papillomaviruses, is required for transactivation and contains several regions of potential amphipathic helix (Giri and Yaniv 1988; McBride et al. 1989b).

Although DNA sites for E2 protein binding are conserved among the different papillomaviruses, the number and position of these sites relative to specific viral promoters differs from one papillomavirus genome to the other (for review, see Sousa et al. 1990). Recent studies have established that there is a great diversity in the responsiveness of different viral promoters to E2. In the case of BPV-1, the promoters upstream of the E6 gene $\left(\mathrm{P}_{89}\right)$ and the E2 gene $\left(\mathrm{P}_{2443}\right)$ are activated by E2 through binding sites located at some distance from these promoters (Spalholz et al. 1987; Hermonat et al. 1988). The situation is similar for the cottontail rabbit papillomavirus (CRPV) in which the major early promoter is also activated by E2 (Giri et al. 1985). In contrast, for the P1 $\left(\mathrm{P}_{7185}\right)$ promoter of BPV-1, interaction of $\mathrm{E} 2$ protein with a single E2-binding site positioned downstream of the transcription start site (Stenlund et al. 1987) has been postulated to interfere with the binding of a positive cellular transcription factor, leading to the repression of this promoter (Stenlund and Botchan 1990). Finally, in the case of the genital tract human papillomaviruses HPV-16 and HPV-18, two E2-binding sites are located in close proximity to viral promoter elements, including one E2-binding site just three nucleotides upstream from the TATA box. Both promoters are repressed by E2 in vivo (Thierry and Yaniv 1987; Bernard et al. 1989; Romanczuk et al. 1990). Furthermore, mutational analysis has recently shown that the most proximal E2-binding site to the TATA box is required for repression of the $\mathrm{P}_{105}$ promoter by BPV-1 E2 in vivo (Romanczuk et al. 1990; Thierry and Howley 1991). The HPV-18 $\mathrm{P}_{105}$ and HPV-16 $\mathrm{P}_{97}$ promoters just upstream of the E6 ORF are responsible for the transcription of the transforming genes E6 and E7 (for review, see Münger et al. 1990). In cervical carcinoma cell lines, the frequent interruption of the E2 ORF by integration of the viral genome is in- terpreted as leading to the derepression of the $\mathrm{P}_{97} \mathrm{HPV}$ 16 and $\mathrm{P}_{105}$ HPV-18 promoters and thereby the potentiation of the expression of the viral E6 and E7 transforming genes (Schwarz et al. 1985; Baker et al. 1987).

The complexity of transcriptional modulation by E2 is increased further by the observation that $\mathrm{E} 2$ in some papillomaviruses may encode multiple polypeptides with different biological activities. This has been best studied in BPV-1 where three distinct proteins, encoded by the E2 ORF, have been identified (Hubbert et al. 1988). All three proteins share the carboxy-terminal domain, but two of them lack the amino-terminal domain of the E2 ORF (Lambert et al. 1989a). These shorter BPV-1 E2 proteins, with intact DNA-binding/dimerization domains, inhibit the activity of the full-length E2 ORF gene product, the E2 trans-activator (Lambert et al. 1987; Choe et al. 1989; Lambert et al. 1990). This inhibition could result from competitive DNA binding or by subunit mixing through the formation of heterodimers with the E2 trans-activator.

To gain additional insight into the molecular basis of differential regulation by a eukaryotic trans-activator, we have used an in vitro transcription system to examine the activity of the purified full-length BPV-1 E2 protein on two different promoters that are either positively or negatively regulated by this protein in vivo. The E2 protein was expressed and purified from the yeast Saccharomyces cerevisiae and added to rat liver nuclear extract as a source of general cellular transcription factors. In this system E2 was shown to be capable of activating transcription of the herpes simplex virus (HSV) thymidine kinase (TK) promoter containing E2 DNA-binding sites in an enhancer configuration or repressing transcription of the $\mathrm{P}_{105}$ promoter of HPV-18, which contains the E2 DNA-binding sites within the promoter region. The activation of the TK promoter and the repression of the $\mathrm{P}_{105}$ promoter were mediated through direct binding of E2 to its target DNA-binding sites. Transcriptional repression of the $\mathrm{P}_{105}$ promoter was relieved by mutation of the E2-binding site most proximal to the TATA box, suggesting that E2 represses transcription by interfering with the formation of the initiation complex. Indeed, incubation of the $\mathrm{P}_{105}$ promoter template with the nuclear extract prior to the addition of E2 prevented the repression of transcription, indicating that once formed, the initiation complex can no longer be dissociated by E2. Finally, band-shift experiments with E2, purified human TFIID expressed in bacteria, and DNA probes containing both $\mathrm{E} 2$ and TFID-binding sites indicate that binding of E2 to its cognate site affected TFIID binding differentially when the distance between respective target sites was modified.

\section{Results \\ Purification of the BPV-1 E2 protein from yeast}

Previous studies have shown that the BPV-1 E2 transactivator can stimulate transcription in yeast from a template containing E2 DNA-binding sites located up- 
stream of a minimal yeast promoter. The basic requirements for viral cis and trans elements were similar in yeast and in mammalian cells (Lambert et al. 1989b; Morrissey et al. 1989; Stanway et al. 1989). This suggested that yeast could be a suitable system for the purification of an intact and functional protein. To test whether it could function directly in vitro as a modulator of transcription, the protein was expressed in yeast and purified by multistep chromatography, including the use of an E2 DNA-binding-site-specific oligonucleotide column (Fig. 1A). Following DNA affinity chromatography, the predominant protein species in the most pure fractions had an apparent molecular mass of $50 \mathrm{kD}$ (Fig. 1B), equivalent to the molecular mass of the intact BPV-1 E2 trans-activator reported previously (Mc Bride et al. 1988; Lambert et al. 1989a).

\section{Purified E2 protein can activate transcription in vitro}

In transfection experiments the full-length BPV-1 E2 protein can activate transcription in vivo, from a TK promoter that contains several E2 DNA-binding sites located $\sim 100$ bp upstream from the transcription start site

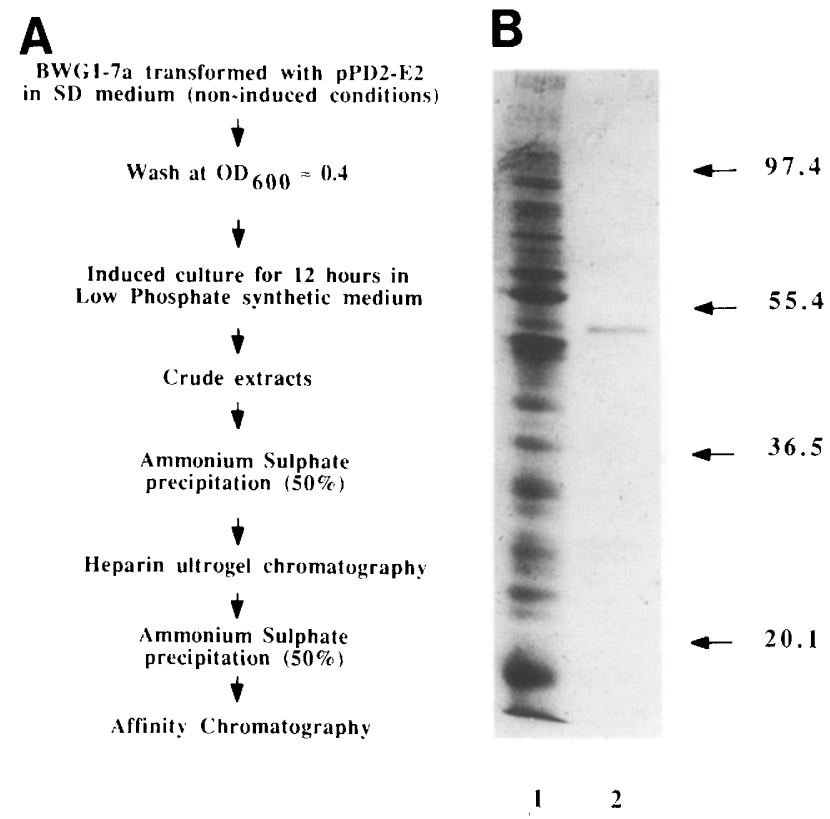

Figure 1. Purification of the BPV-1 E2 protein. (A) Steps of E2 purification. E2-binding activity during the purification was monitored by a gel-shift assay with a double-stranded oligonucleotide (CTAGACCGAAAACGGTGCTAG) containing one E2-binding site. The affinity column was prepared with polymers of this oligonucleotide. (B) SDS-PAGE analysis of protein content before and after purification. (Lane 1) $9 \mu \mathrm{g}$ of crude extract from an induced yeast culture expressing the $50-\mathrm{kD} \mathrm{E} 2$; (lane 2): $7 \mu$ l of an active fraction from the affinity column. The relative E2-binding activity measured by gel retardation is 0.6 units for the crude extract (lane 1) and 300 units for the fraction shown in lane 2. The gel was stained with Coomassie blue; the molecular mass markers are indicated at right.
(Thierry et al. 1990). To test whether the purified E2 trans-activator protein could function as an activator in vitro, the protein was added to a cell-free transcription system composed of a rat liver nuclear extract. Transcription was measured with "G-free" templates in which the TK promoter is positioned immediately upstream of a stretch of DNA containing no G residues in the coding strand (Sawadogo and Roeder 1985). The test templates contained the TK promoter with either none, one, two, or six copies of the E2-binding site. Each of these plasmids generated an in vitro product of $375 \mathrm{nu}-$ cleotides (Fig. 2). A control template containing the TK promoter with no E2-binding site that generates a transcript of 247 nucleotides was included in each reaction. The different TK templates were comparable in their capacity to direct RNA synthesis in in vitro transcription reactions with liver extracts alone (Fig. 3A, lanes 1 and $5)$. When increasing amounts of purified E2 protein were added to the reaction, however, there was a specific and dose-dependent induction of the RNA synthesis level from the plasmid template containing six E2 DNA-binding sites upstream of the TK promoter (Fig. 3A, lanes 6-8). The addition of $E 2$ protein had no detectable effect on control templates lacking E2 DNA-binding sites (Fig. $3 \mathrm{~A}$, lanes 2-4). Thus, the increase in the transcriptional efficiency $(\sim 3-$ to 3.5 -fold at the highest E2 concentration) was specifically observed with templates containing E2-binding sites. Maximal stimulation by E2 was obtained with a 10-fold ratio of the E2 DNA-binding activity over the number of DNA-binding sites, as determined by gel-shift assays. It should be noted, however, that the level of activation by E2 in this in vitro system, while reproducible, was significantly lower than the effect observed in vivo in mammalian cells (20- to 50-fold) (Thierry et al. 1990) or in yeast (50- to 250-fold) (Lambert et al. $1989 \mathrm{~b})$.

An interesting feature of trans-activation by E2 protein in vivo is that although E2 can bind strongly to a single palindromic site (Dostatni et al. 1988; Lambert et al. 1989 b), this single site constitutes only a weak E2dependent enhancer. A strong synergistic effect is observed between two sites either in mammalian cells (Harrison et al. 1987; Hawley-Nelson et al. 1988; Spalholz et al. 1988; Thierry et al. 1990) or in yeast (Lambert et al. 1989a; Morrissey et al. 1989; Stanway et al. 1989). To determine whether E2 transcriptional activation in vitro follows the same rules as in vivo, different test templates containing one, two, or six E2-binding sites were assayed for their in vitro E2-mediated stimulation. As shown in Figure $3 \mathrm{~B}$, there was a modest (twofold) increase in the level of E2 stimulation with increasing numbers of E2-binding sites upstream of the TK promoter. However, this difference does not account, this for the strong synergism seen in cotransfected cells with multiple E2 DNA-binding sites.

\section{Binding of E2 is required for in vitro activation of the TK promoter}

To confirm that the stimulation by E2 was caused by 


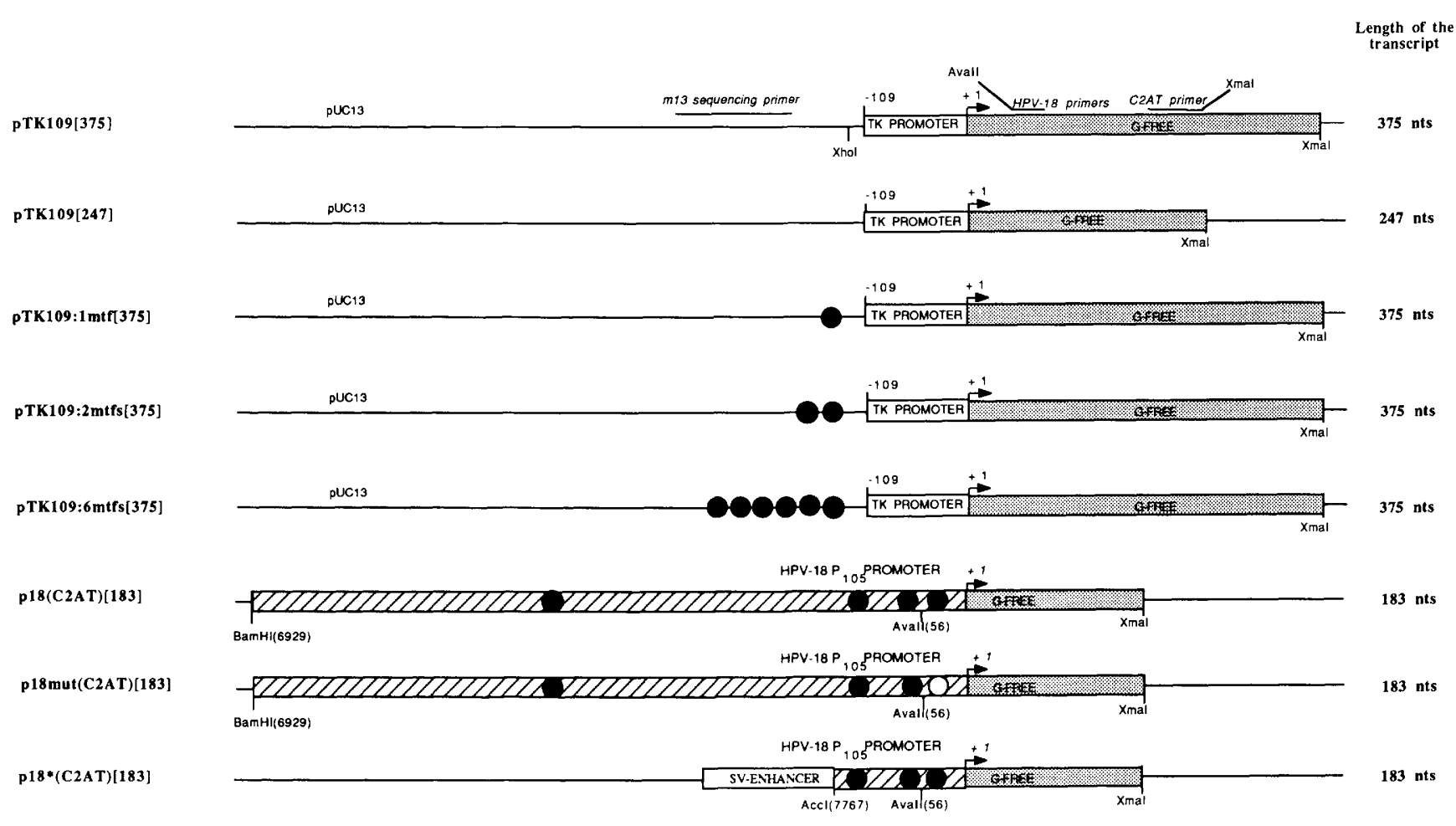

Figure 2. Structure of the DNA templates used for in vitro transcription. The schematic structure of the promoters driving the G-free cassette (shaded box) is indicated. Names of the plasmids are given at left, and the specific length of the G-free transcripts at right. In the pTK 109 plasmids, the TK promoter $\mid-109$ to +5$)$ drives the expression of G-free cassettes with lengths of either 375 or 247 nucleotides. In the p18 plasmid a fragment of the HPV-18 genome containing the entire long control region (nucleotides 6929-105) was inserted in front of a 183-nucleotide-long G-free cassette. In p18mut, the E2-binding site at position 58 was mutated. In the construction $\mathrm{p} 18^{*}\left(\mathrm{C}_{2} \mathrm{AT}\right)$ a fragment of DNA containing the 72-bp repeats of the SV40 enhancer was inserted at the AccI restriction site at position 7767 of the HPV-18 genome. Nucleotide numbering of the HPV-18 sequence is given by Cole and Danos (1987). (O) The wild-type E2-binding sites; (O) the mutated site. Positions of the primers used for amplification of G-free sequences are indicated.

binding of the $\mathrm{E} 2$ protein to its DNA target, competition experiments were performed with either an oligonucleotide containing two copies of the E2 DNA-binding site or an oligonucleotide containing an unrelated sequence. In this experiment E2 protein was mixed with the DNA templates and oligonucleotides before addition of either the extract or the nucleotides to initiate the transcription reactions. The transcriptional stimulation of the test product (375 nucleotides) by E2 was completely abolished by the addition of $100 \mathrm{ng}$ of the specific competitor oligonucleotide (Fig. 4, lanes 3 and 4). In contrast, E2 was still able to induce transcription of this template in the presence of the nonspecific competitor oligonucleotide (Fig. 4, lanes 5 and 6). The presence of either of these oligonucleotides reduced the overall level of transcription approximately fivefold. Nevertheless, only the specific competitor was capable of abrogating the E2specific trans-activation of the target plasmid containing E2 DNA-binding sites.

E2 represses transcription of the HPV-18 $P_{105}$ promoter in vitro

In mammalian cells the full-length BPV-1 E2 gene product can repress the HPV-18 $\mathrm{P}_{105}$ promoter, which is re- sponsible for the expression of the E6 and E7 transforming functions (Thierry and Yaniv 1987; Romanczuk et al. 1990). Although it is likely that the repression of the HPV-18 $\mathrm{P}_{105}$ promoter in cotransfection experiments was caused by the full-length product of the E2 ORF, it remained possible that a carboxy-terminal truncated form of the E2 protein could be expressed in these cells and act dominantly as a transcriptional repressor (Lambert et al. 1987). To test whether the purified full-length E2 protein could repress transcription of the HPV-18 $\mathrm{P}_{105}$ promoter in vitro, templates containing this promoter upstream of the G-free cassette were constructed and assayed for in vitro transcription in the presence or absence of E2. As depicted in Figure 2, two different templates containing the wild-type E2-binding sites were used: p 18 contains the entire regulatory region of HPV18 , whereas $\mathrm{pl} 8^{*}$ contains the SV40 enhancer inserted $\sim 200$ nucleotides upstream of the $\mathrm{P}_{105}$ cap site. In each of these plasmids, the promoter was cloned upstream of a short G-free cassette of 183 nucleotides. The $P_{105}$ templates were assayed for in vitro transcription in rat liver extracts by using, as internal control, a TK template generating a product of 247 nucleotides. Similar levels of transcription from the $\mathrm{P}_{105}$ promoter were obtained for P18 and P18* (Fig. 5, cf. A and B). This result indicated 
A

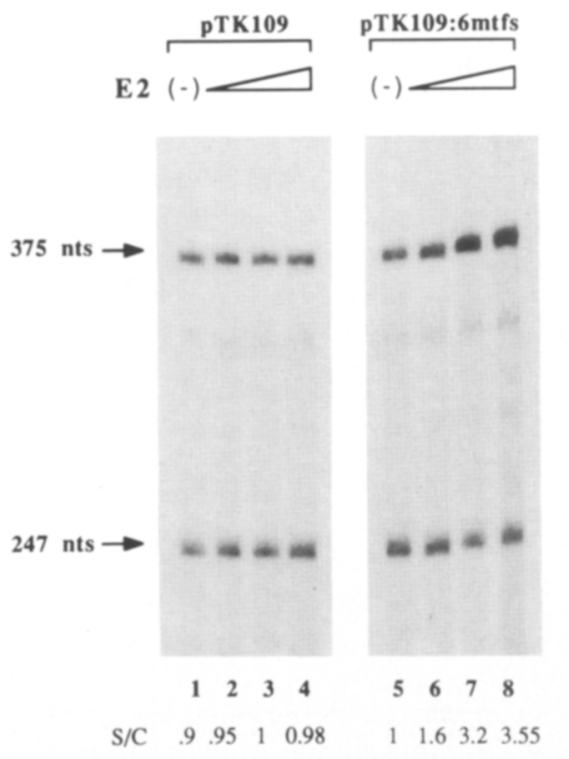

B

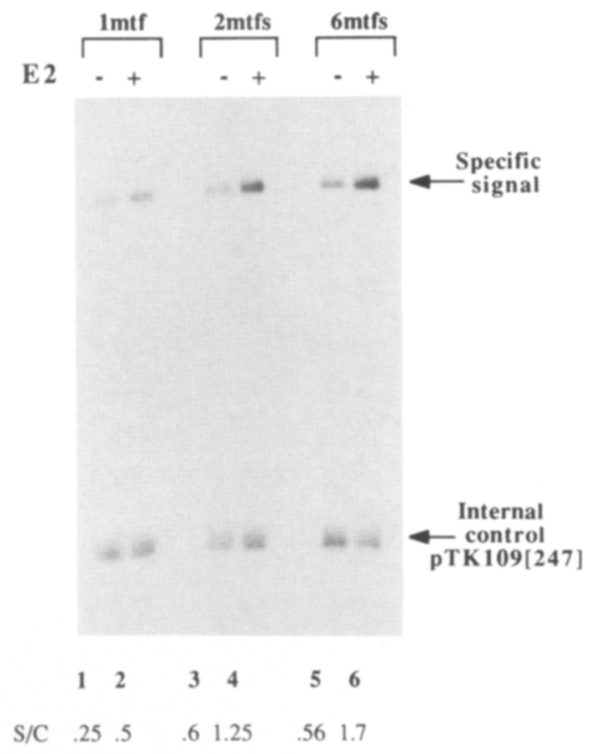

Figure 3. In vitro stimulation of the TK promoter by E2. $(A)$ In vitro stimulation of the TK promoter by E2 requires the presence of E2-binding sites in the promoter and is dose dependent. In vitro transcription experiments were carried out with $50 \mathrm{ng}$ of the plasmid pTK109[247] as an internal control and $200 \mathrm{ng}$ of Bluescribe plasmid as carrier DNA; $50 \mathrm{ng}$ of pTK109[375] (lanes 1-4) and 50 ng of pTK109: 6mtfs[375] (lanes 5-8) as specific templates. Increasing amounts of E2 [(lanes 1,5) 0 unit; (lanes 2,6) 0.7 unit; (lanes 3,7) 3.5 units; (lanes 4,8) 14 units] were mixed rapidly on ice with the DNA templates before addition of $30 \mu \mathrm{g}$ of nuclear extract and the nucleotides. The ratios of the two signals obtained with the specific template ( 375 nucleotides) and the internal control (247 nucleotides) determined by scanning the autoradiogram are indicated at bottom. (B) Effect of the number of E2-binding sites upstream of the TK promoter. Purified E2 (14 units) (lanes 2,4,6) or the same volume of dialysis buffer (lanes 1, 3,5) was first mixed with the DNA (250 ng of Bluescribe as carrier, $100 \mathrm{ng}$ of TK109|247] as internal control, and $50 \mathrm{ng}$ of the specific templates TK109:1mtf[375] in lanes 1 and 2; TK109:2mtfs[375] in lanes 3 and 4; TK109:6mtfs[375] in lanes 5 and 6) before adding the liver extract (60 $\mu \mathrm{g})$. In vitro transcription reactions were initiated by the addition of nucleotides. Quantitative values obtained by scanning of the autoradiogram to determine the ratio of the specific signal (375 nucleotides) to the signal of the internal control (247 nucleotides) are indicated at bottom.

that the SV40 enhancer and the upstream sequences of the HPV-18 long-control region have similar effects on transcription of the $\mathrm{P}_{105}$ promoter in vitro. Because the levels of transcriptional efficiency of both templates were low, it is highly probable that these activities reflect the basal level of the promoter and that none of the cellular factor(s) interacting with the two different enhancer sequences are present or active in the in vitro system. In the presence of increasing amounts of E2, as shown in Figure 5A, the levels of the $\mathrm{P}_{105}$-specific product (183 nucleotides) decreased, whereas the signal for the product of the internal control (247 nucleotides) was not affected by addition of $\mathrm{E} 2$. Transcriptional repression of the $\mathrm{P}_{105}$ promoter by $\mathrm{E} 2$ appeared dose dependent, and the dose requirements of E2 protein were comparable for either the in vitro activation of the TK promoter containing E2-binding sites or the repression of the HPV-18 $\mathrm{P}_{105}$ promoter.

Binding of E2 to its cognate sequence proximal to the TATA box of the $P_{105}$ promoter of HPV-18 is necessary for repression in vitro

Transcriptional repression of the HPV-18 $\mathrm{P}_{105}$ promoter in vivo by BPV-1 E2 is mediated through the E2-binding site immediately proximal to the TATA box (Romanczuk et al. 1990; Thierry and Howley 1991). To determine whether the repression of this promoter observed in vitro was due to the binding of E2 to the same site, we used a plasmid template containing a mutated version of the $\mathrm{P}_{105}$ promoter in which the E2-binding site proximal to the TATA box had been changed so that it no longer bound E2 (depicted in Fig. 2). As shown in Figure 5B, the basal transcriptional activities of the wild-type and $\mathrm{mu}$ tated promoters in liver extracts were similar. In the context of the complete long control region, only the wildtype $P_{105}$ promoter could be repressed by E2 to levels similar to those of the p18* plasmid (Fig. 5A,B). The mutated plasmid p18mut was not affected by the addition of E2. Therefore, the purified full-length BPV-1 E2 could directly repress transcription of the $P_{105}$ promoter of HPV-18 through binding to its cognate sequence immediately proximal to the TATA box.

Preincubation of the HPV-18 template with nuclear extract prevents repression by E2

In the HPV-18 $\mathrm{P}_{105}$ promoter, the E2-binding site proxi- 


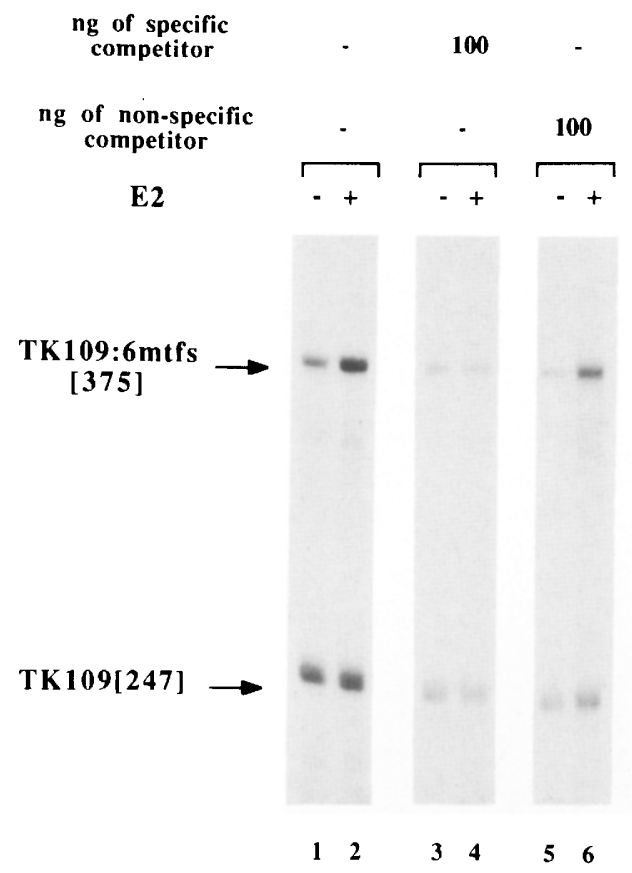

Figure 4. Oligonucleotide competition of E2 stimulation in vitro. Fifty nanograms of the pTK $109: 6 \mathrm{mtfs} \mid 375]$-specific template, $100 \mathrm{ng}$ of the pTK109[247] internal control, and $250 \mathrm{ng}$ of the Bluescribe plasmid were mixed with the different oligonucleotides as indicated: no competitor oligonucleotide in lanes 1 and 2; $100 \mathrm{ng}$ of an oligonucleotide containing two E2-binding sites in lanes 3 and 4; and $100 \mathrm{ng}$ of an unrelated oligonucleotide in lanes 5 and 6 . This amount of specific competitor oligonucleotide corresponds to a $\sim 50$-fold molar excess of specific E2binding sites. Fourteen units of purified E2 (lanes 2,4,6) or the same volume of dialysis buffer (lanes $1,3,5)$ was mixed with the DNA prior to the addition of $60 \mu \mathrm{g}$ of rat liver extract. The transcription reactions were initiated by addition of the nucleotides. The ratios of the scanning values between the specific (375 nucleotides) and control (247 nucleotides) signals were 0.43 (lane 1), 0.93 (lane 2), 0.38 (lane 3), 0.43 (lane 4), 0.43 (lane 5), and 0.93 (lane 6). The levels of stimulation were 2.2 -fold without competitor oligonucleotide, 1.1 -fold with excess of the specific oligonucleotide, and 2.2-fold with excess of the unrelated oligonucleotide.

mal to the transcription start site is separated from the TATA box by only three nucleotides. DNase I footprinting experiments have shown that E2 binding to this site partly overlaps the TATA box region (Garcia-Carranca et al. 1988), and it was suggested that repression of this promoter by $\mathrm{E} 2$ could be due to steric interference with the formation of an active transcription complex. The in vitro transcription system provided an opportunity to test this hypothesis directly. Preincubation of the template with the nuclear extract should lead to the formation of a committed complex, resistant to repression by E2. As shown in Figure 6, when liver nuclear extract was first incubated for $30 \mathrm{~min}$ with the test template, p18, prior to the addition of E2 protein and nucleotides to start transcription, no repression of the HPV-18 promoter by E2 was detected. In contrast, when E2 was ad- ded to the preincubation at the same time as the nuclear extract and transcription was initiated 30 min later by addition of nucleotides, transcription from the wild-type $\mathrm{P}_{105}$ promoter was repressed (Fig. 6, lanes 2 and 3). The activity of the mutated $P_{105}$ promoter was not affected significantly in this experiment, confirming that the effect observed depends on the binding of $\mathrm{E} 2$ protein to its cognate site proximal to the TATA box (Fig. 6, lanes 6,7).

Binding of E2 to its DNA site near the TATA box of the HPV-18 $P_{105}$ promoter modifies the binding of TFIID to its cognate site

The template commitment experiment described above demonstrated that the E2-mediated repression of the HPV-18 $\mathrm{P}_{105}$ promoter was probably due to interference with the formation of the initiation complex. As the E2binding site responsible for this repression and the TATA box of the $P_{105}$ promoter are very close to each other, it was plausible that this effect was due to direct DNA-binding competition between E2 and TFIID for their respective cognate sites. Alternatively, E2 could interfere with the binding of an essential cellular factor next to the TATA element. Competitive binding between E2 and a positive-acting transcriptional factor has been suggested for the BPV-1 P1 $\left(\mathrm{P}_{7185}\right)$ promoter (Stenlund and Botchan 1990) and has been described for a constitutive enhancer in the vicinity of this promoter in BPV-1 (Van de Pol and Howley 1990). To distinguish between these alternative mechanisms, DNA-binding band-shift assays were performed with E2 and human TFIID purified from Escherichia coli, a kind gift from $\mathrm{F}$. Pugh and R. Tjian (Peterson et al. 1990) and different DNA probes that are 36-41 nucleotides long. A first one was called E2T and contained the exact sequence of the HPV-18 $\mathrm{P}_{105}$ promoter spanning the crucial E2-binding site (position 58) and the TATA box (position 72). A second one, called E2- $\mathrm{N}_{5}-\mathrm{T}$, was similar to E2T but contained an insertion of five additional nucleotides between the crucial E2-binding site and the TATA box of the $\mathrm{P}_{105}$ promoter. Finally, two probes called E2MT and E2TM were similar to E2T but contained double point mutations affecting, respectively, E2 or TFIID binding. The results of the band-shift assays are described in Figure 7.

The binding of TFIID to E2T, E2-N5-T, and E2MT probes gave rise to a slow migrating complex (Fig. 7A, lanes 2,10; Fig. 7B, lane 2), whereas the binding of E2 to the E2T, E2-N5-T, and E2TM probes gave rise to a faster migrating complex (Fig. 7A,B, lanes 6-8 and 14-16). As expected, the E2 protein and TFIID were unable to bind to the probes containing mutations in their respective cognate sites (Fig. 7B, lanes 6-8 for E2 and lane 10 for TFIID). As shown in Figure 7A (lanes 3-5), increasing the amount of $\mathrm{E} 2$ in the incubation destabilized the binding of TFIID to the probe E2T with the appearence of some smearing in the gel. This effect was not observed when the two binding sites for E2 and TFIID were separated by five additional nucleotides as they were in probe E2- 
A

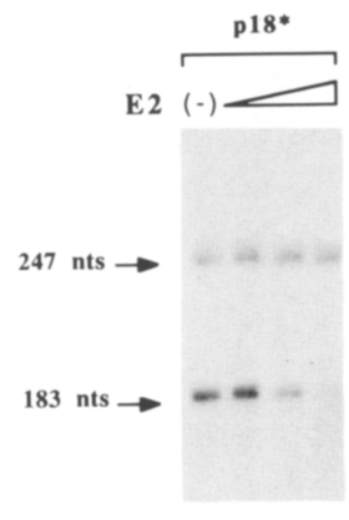

$\begin{array}{llll}1 & 2 & 3 & 4\end{array}$
B

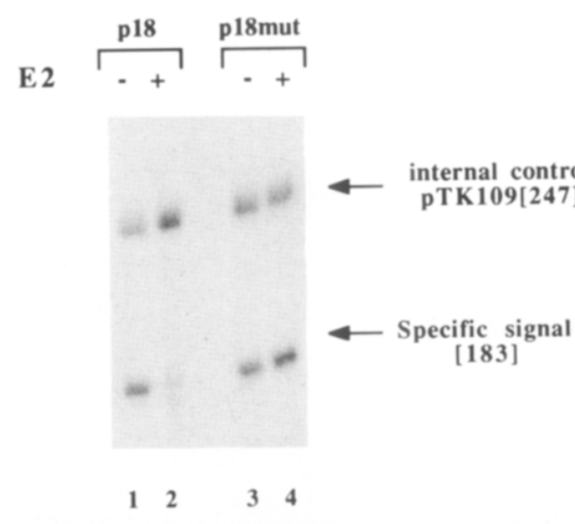

Figure 5. In vitro repression of the $P_{105}$ promoter by the full-length E2. (A) Repression by $\mathrm{E} 2$ of the $\mathrm{P}_{105}$ promoter is dose dependent. For the dose-response experiment, $50 \mathrm{ng}$ of the pl8 ${ }^{\star}\left(\mathrm{C}_{2} \mathrm{AT}\right)[183]$ construction was used as specific template with $50 \mathrm{ng}$ of the pTK109[247] internal control and $200 \mathrm{ng}$ of the Bluescribe plasmid. Different amounts of E2 [(lane 1) 0 unit; (lane 2) 0.7 unit; (lane 3) 3.5 units; (lane 4) 14 units] were mixed rapidly with the DNA templates on ice before adding $30 \mu \mathrm{g}$ of nuclear extract and the nucleotides. The ratios of the scanning values between the specific (183) and control (247) signals were 1.7 (lane 1), 2 (lane 2), 0.8 (lane 3), and 0.16 (lane 4). The level of repression reached 11-fold at the highest concentration of E2. (B) Binding of E2 to the E2-binding site proximal to the TATA box is required for repression of the $\mathrm{P}_{105}$ promoter. Fourteen units of purified E2 (lanes 2,4 ) or the same volume of dialysis buffer (lanes 1,3) was first mixed with the DNA (250 ng of the Bluescribe plasmid, $100 \mathrm{ng}$ of the TK109[247] as internal control, and $50 \mathrm{ng}$ of the specific templates p18(C2AT)[183] (lanes 1,2) or p18mut $\left(\mathrm{C}_{2} \mathrm{AT}\right)[183]$ (lanes 3,4) before the addition of the liver extract $(60$ $\mu \mathrm{g}$ ). The reactions were initiated by addition of the nucleotides. The ratios between the specific (183) and the control (247) signals were 0.62 (lane 1), $\leqslant 0.08$ (lane 2), 0.9 (lane 3), and 1 (lane 4).

N5-T (Fig. 7A, lanes 9-16). On the contrary, the intensity of the band migrating at the position of the original TFIID complex clearly increased in a dose-dependent manner in the presence of E2 (Fig. 7A, lanes 11-13), whereas the intensity of the band migrating at the posi- tion of $\mathrm{E} 2$ bound alone to the probe decreased (Fig. 7A, cf. lanes 11-13 with lanes 14-16 respectively). Experiments described below argue strongly that the major shifted band observed in lanes 11-13 actually contained both proteins bound simultaneously to the same probe. The
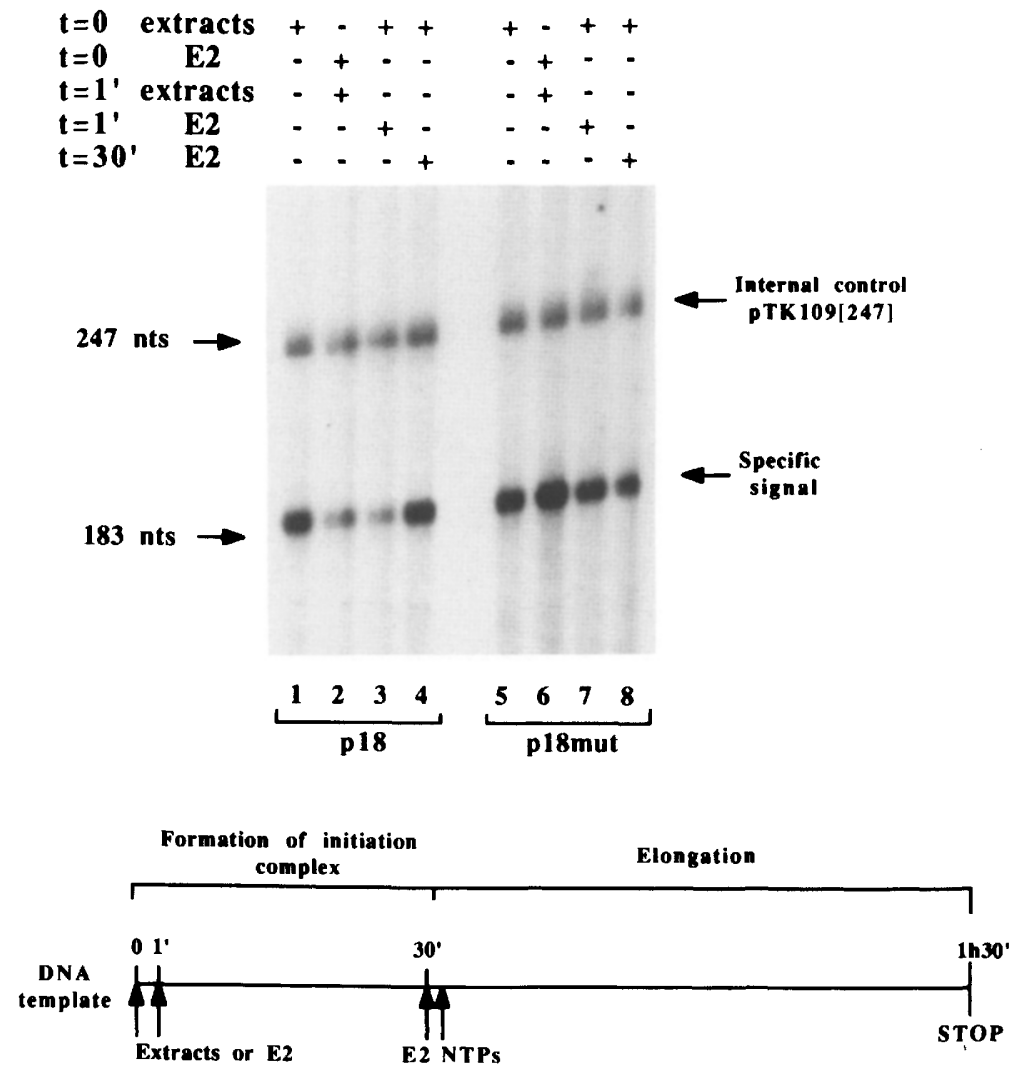

Figure 6. E2 cannot dissociate a preformed initiation complex. Incubations took place at $30^{\circ} \mathrm{C}$ in the required buffer with $100 \mathrm{ng}$ of the specific templates p18[183] (lanes 1-4) or pl8mut[183] (lanes 5-8), 50 ng of the control template pTK109[247], $250 \mathrm{ng}$ of the Bluescribe plasmid, $60 \mu \mathrm{g}$ of rat liver nuclear extract, and 14 units of purified E2 as indicated. E2 and the nuclear extract were added at the indicated times schematically represented at bottom. If no E2 was added, the same volume of dialysis buffer containing $0.5 \mu \mathrm{g} / \mu \mathrm{l}$ of BSA was added to the incubation sample. The transcription reactions were initiated after $30 \mathrm{~min}$ by the addition of nucleotides. Quantitative values obtained after scanning of the film for the ratio between the specific signal $(183)$ and the internal control (247) were 3.15 (lane 1), 0.8 (lane 2), 0.6 (lane 3), 2.4 (lane 4), 2.6 (lane 5), 5.3 (lane 6), 2.9 (lane 7), and 1.35 (lane 8). 
A

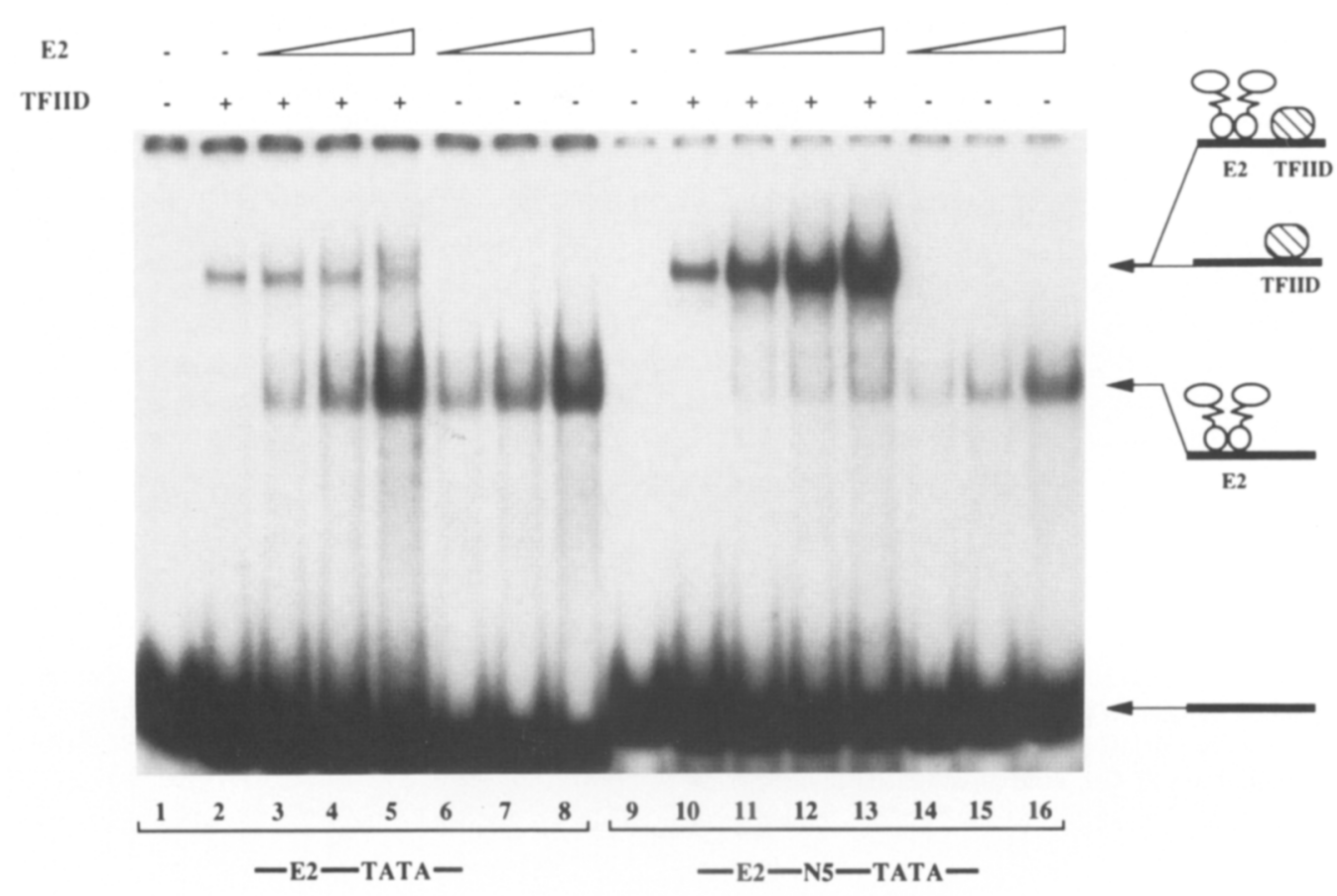

B

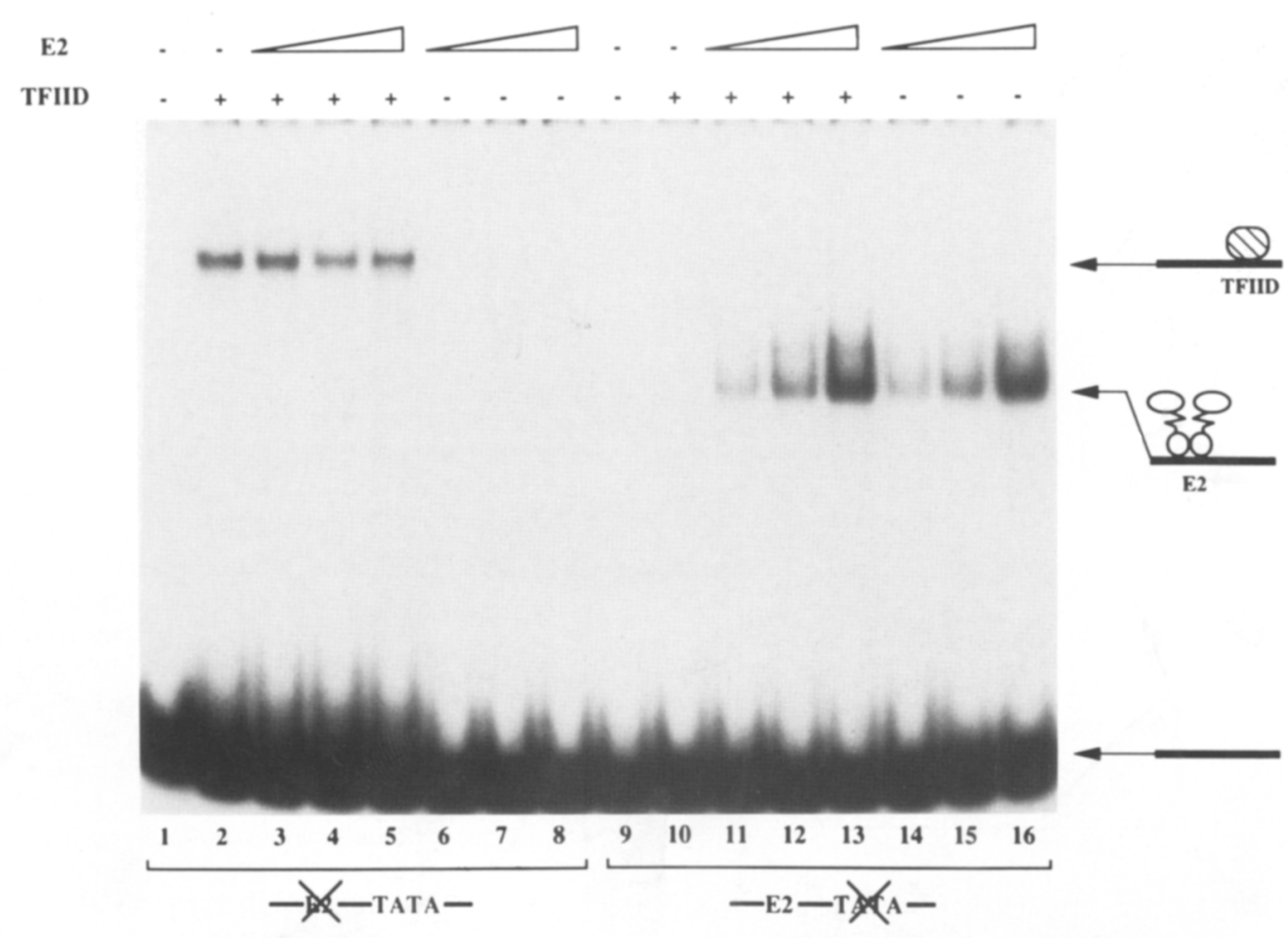

Figure 7. Binding of E2 can affect the binding of TFIID differentially, depending on the distance between respective DNA cognate sites. Twenty-five picograms of the indicated probe was incubated with different amounts of E2 $[A, B($ lanes $3,6,11,14) 0.5 \mathrm{ng}$; (lanes $4,7,12,15) 1 \mathrm{ng}$; (lanes 5,8,13,16) $2 \mathrm{ng}]$ and $4 \mathrm{ng}$ of TFIID $[A, B$ (lanes 2-5,10-13)]. When no E2 or TFIID was used, the same volume of protein dilution buffer was added. Position of the three different complexes observed is indicated at right, with a schematic representation of the components of each complex (not to scale). The E2 protein is schematically drawn as two open globular domains linked by a flexible unstructured domain; and TFIID is represented by the hatched globular domain. 
E2-mediated effect on TFIID binding obtained with E2T and E2-N5-T probes was not observed when the probe was mutated either in the TATA box (Fig. 7B, lanes 3-5) or in the E2-binding site (Fig. 7B, lanes 11-13), indicating that they are both dependent on specific DNA binding of E2 and TFIID to their respective target sites.

Finally, it is interesting to note that the relative migration of the E2 and TFIID complexes is not a function of their molecular mass. As demonstrated by the Western blot shown in Figure 8A, the E2 protein used in this study had the molecular mass expected for intact E2 and had migrated to a position identical to that of baculovirus-expressed E2. Although the complex containing a dimer of intact $\mathrm{E} 2$ has a molecular mass of $2 \times 50 \mathrm{kD}$, it migrated faster than the TFIID $(30 \mathrm{kD})$-containing complex in gel shift experiments.

\section{E2 protein and TFIID can bind simultaneously} to the probe containing five additional nucleotides between the E2-binding site and the TATA box

As described previously, the presence of E2 in the gelshift experiment made with the probe containing five additional nucleotides between the E2-binding site and the TATA box (E2-N5-T) strongly increased the intensity of the band observed when TFIID was bound alone to the probe. This effect was not observed when the E2binding site was mutated as in the probe E2MT (cf. Fig. 7A, lanes 11-13 with Fig. 7B, lanes 11-13). This observation indicates that specific binding of $\mathrm{E} 2$ is required for this effect and suggests that binding of E2 to this particular probe indeed stimulates or stabilizes binding of TFIID to the TATA box. The E2 protein and TFIID might then be bound simultaneously on the probe containing five additional nucleotides between the E2-binding site and the TATA box, even though the ternary complex containing both E2 and TFIID bound to the same probe appears to migrate at the same position as the original one obtained with TFIID alone.

The presence of E2 in this complex is supported by the following observations. (1) When a similar experiment was done with a truncated E2 protein, a third additional band migrating slightly below the band corresponding to the original TFIID complex was observed (data not shown). (2) dimethyl sulfate (DMS) interference experiments performed with this probe indicate that methyl-

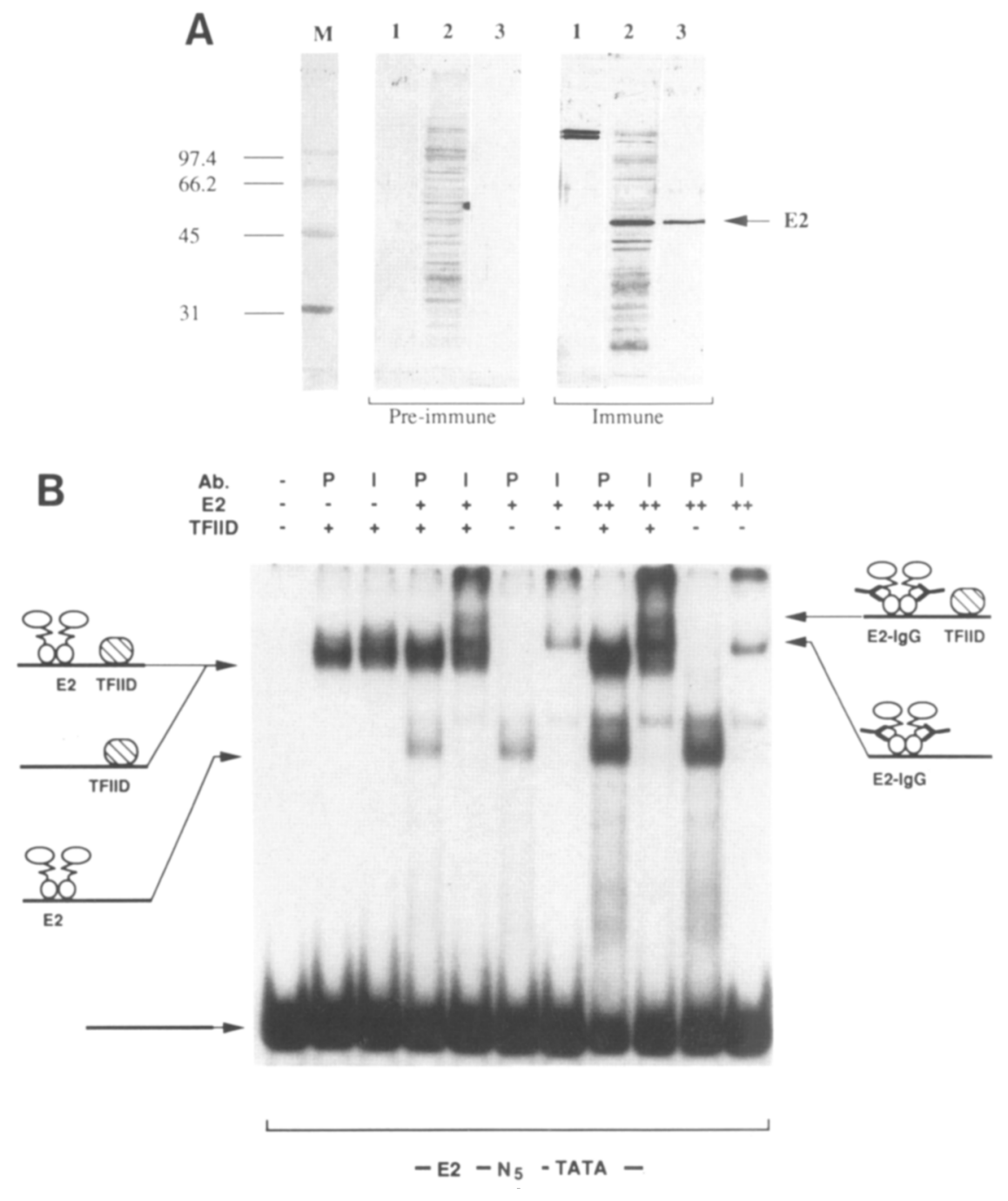

Figure 8. E2 and TFIID may bind simultaneously on the $\mathrm{E} 2-\mathrm{N}_{5}-\mathrm{T}$ probe. $(A)$ Western blot analysis of the E2 preparation. Different preparations of E2 were analyzed by SDS-PAGE. (Lane 1) A purified fusion protein between $\beta$-galactosidase and the carboxy-terminal part of E2; (lane 2) whole-cell extract of baculovirus-infected cells expressing full-length E2; (lane 3) $150 \mathrm{ng}$ of the purified yeast purified E2. As indicated, each gel was incubated with either preimmune or immune serum. Positions of molecular mass markers are indicated at left; the position of the fulllength $\mathrm{E} 2$ is shown with an arrow at right. (B) Gel-shift assay with anti-E2 antibodies. The probe used for this experiment was E2-N $\mathrm{N}_{5}-\mathrm{T}$. Fifty picograms of probe was incubated with 2 ng of TFIID (lanes 2-5, 8-9) and different amounts of E2 [(lanes 4-7) 2 ng; (lanes 8-11) $8 \mathrm{ng}$ ). When no E2 (lanes 1-3) or TFIID (lanes 1,6-7,10-11) was used, the same volume of protein dilution buffer was added. After binding incubation for $30 \mathrm{~min}$ at $30^{\circ} \mathrm{C}, 1 \mu \mathrm{l}$ of the preimmune serum (lanes $2,4,6,8,10$ ) or $1 \mu \mathrm{l}$ of the immune antiserum (lanes $3,5,7,9,11$ ) was added to the mixture and the incubation was performed for $15 \mathrm{~min}$ at room temperature before loading. Positions of the different complexes are indicated as well as a schematic representation of the components of each (not to scale). IgG bound to E2 is represented by black forks. 
ation of guanines known to be crucial for E2 binding (Dostatni et al. 1988; Moskaluk and Bastia 1988b) interfere with the formation of this ternary complex (data not shown). (3) Further evidence came from gel-shift assays performed with the E2 and TFIID proteins in the presence of a polyclonal antibody directed against the DNAbinding domain of the E2 protein. As shown in Figure 8B, the presence of the specific antiserum had no significant effect on the migration of the complex obtained with TFIID alone (Fig. 8B, cf. lanes 2 and 3 ). In contrast, the presence of the specific antiserum led to a shift of the complex obtained with the E2 protein alone (Fig. 8B, cf. lanes 6 and 10 with lanes 7 and 11): The supershifted complex observed in lanes 7 and 11 likely corresponds to the complex formed between the labeled DNA probe and E2 molecules, which are themselves bound by the antibodies. The same experiment was repeated in the presence of both E2 and TFIID with two different E2 concentrations (Fig. 8B, lanes 4,5 and lanes 8,9 ). The band shifts shown in lanes 4 and 8 were done in the presence of preimmune serum and gave similar patterns to those in Figure 7A, lanes 11-13. In contrast, the use of the specific antiserum in lanes 5 and 9 led to a clear slowing down (supershift) of the presumed ternary complex. Among the three bands discernible, the intermediate one migrated at the same position of the supershifted band obtained with E2 alone and the specific antiserum (as in lanes 7 and 11). The faster one migrated at the same position as the complex formed with TFIID alone while the slowest one is likely to be a supershift induced by binding of the IgG in the ternary complex formed by E2 and TFIID bound together to the same probe. These experiments provided further support that an additional complex can be obtained in the gel shift with the E2$\mathrm{N}_{5}-\mathrm{T}$ probe in which E2 and TFIID were bound simultaneously to the same probe. Similar experiments made with the specific anti-E2 serum revealed that such a ternary complex was not detectable with the wild-type E2T probe when the E2-binding site and the TATA box were separated by only three nucleotides as in the $\mathrm{P}_{105}$ promoter of HPV-18 (data not shown). These results established that simultaneous binding of E2 and TFIID cannot occur efficiently on the $P_{105}$ promoter of HPV-18 under our experimental conditions.

\section{Discussion}

The E2 proteins encoded by the papillomaviruses bind to a specific DNA sequence repeated multiple times in the genomes of all papillomaviruses. The presence of these E2 DNA-binding sites in cis is necessary for transcriptional modulation of viral promoters by E2 proteins in vivo. The nature of the regulation, be it activation or repression, depends on the position of the E2-binding sites relative to promoter elements and on the nature of the E2 gene product itself. In this study the capacity of the full-length BPV-1 E2 protein to act directly on transcription as an activator and as a repressor in vitro was investigated.
The full-length purified BPV1 E2 trans-activator is functional in vitro

E2 trans-activation of the TK promoter in vitro was dependent on the presence of at least one E2 DNA-binding site inserted upstream of the promoter sequences in the reporter plasmids and was dose dependent. Nevertheless, there were differences in the activities observed in vitro compared to those measured in vivo. The stimulation of the TK promoter by E2 reached only three- to fourfold in our system with rat liver nuclear extracts. Similar levels of activation were observed with E2 and HeLa whole-cell extracts (data not shown). These levels of activation are significantly lower than those generally observed in transient transfection experiments (Thierry et al. 1990). In addition, the levels of stimulation of the TK promoter obtained with templates containing one or multiple E2binding sites were comparable in vitro, although a very high synergy between two E2 dimers is characteristic of E2 trans-activation in transfected cells (Gauthier et al. 1991).

The amino-terminal trans-activation domain of E2 contains two regions with potential amphipathic $\alpha$-helices, a conserved structure presumed to be responsible for the interaction of activators with the transcriptional machinery (Hope et al. 1988). Synergy, in the case of E2 trans-activation, is thought to reflect the cooperative interaction of multiple-bound E2 protein molecules with the cellular machinery via their amino-terminal domains (Lambert et al. 1989a). The lack of synergy in vitro might be due to the $\mathrm{E} 2$ protein itself being modified improperly. It is also possible that some of the cellular factors required for E2 stimulation are labile or in limiting amounts in the extracts. The low level of activation and the lack of synergy by trans-activators commonly observed in vitro may represent a fundamental difference between in vitro and in vivo assays, such as the possibility that trans-activators play a dual role in vivo of both derepressing as well as activating promoters (Croston et al. 1991; Workman et al. 1991).

\section{E2 represses in vitro transcription of the HPV-18 $P_{105}$ promoter}

The $\mathrm{P}_{105}$ promoter of HPV18 directs the transcription of the transforming genes E6 and E7 that have been implicated in cervical carcinoma. This promoter was active in vitro with a detectable basal level in cell extracts from rat liver, and its transcription was repressed in vitro by full-length BPV-1 E2. The 10-fold repression was mediated through E2 binding to the DNA target just proximal to the TATA box of the promoter, the same site that is involved in vivo in the repression of this promoter (Thierry and Yaniv 1987; Romanczuk et al. 1990; Thierry and Howley 1991). Previous studies (Thierry and Yaniv 1987; Garcia-Carranca et al. 1988; Romanczuk et al. 1990; Thierry and Howley 1991) led to the proposal that the mechanism of E2 repression of the $\mathrm{P}_{105}$ promoter involves the direct inhibition of the formation of the transcription initiation complex. To test this hy- 
pothesis, we preincubated the HPV-18 template with the nuclear extract, prior to addition of the E2 protein. No repression was observed upon E2 addition, showing that once a committed template is formed, the full-length BPV-1 E2 is no longer able to repress transcription of this promoter. Repression by E2 thus appears to occur at an early step during the assembly of the initiation complex on this promoter. Because truncated E2 proteins containing only the DNA-binding/dimerization domain are still able to repress transcription of $\mathrm{P}_{105}$ in vivo (Thierry and Howley 1991), the mechanism of repression appeared to be linked to the capacity of the E2 protein to bind DNA. The E2 DNA-binding site responsible for E2 repression of the $\mathrm{P}_{105}$ promoter is adjacent to the TATA box, and it was suggested that binding of E2 to this site may interfere by steric hindrance with the formation or the stabilization of the initiation complex. A simple explanation of this effect would be competitive binding between E2 and TFIID for the promoter at their respective target sites, which are separated only by three nucleotides.

\section{The distance between the E2-binding site and the TATA box can modify the effect of E2 on TFIID binding}

In an attempt to understand the opposing properties of E2 at the molecular level, we performed gel-shift experiments using both purified E2 and TFIID. Several DNA probes were used in which the E2-binding site and a TATA box were either placed at different distances from each other or were individually mutated. Our experiments indicate that the specific binding of E2 on its cognate site may affect the binding of TFIID on the TATA box differently, depending on the distance between the latter and the E2-binding site. When both sites were as close as in the $\mathrm{P}_{105}$ promoter of HPV-18, the yield of the TFIID-containing complex partially decreased upon addition of E2 as if both proteins could not bind simultaneously to the same probe. E2-mediated repression of the HPV-18 $\mathrm{P}_{105}$ promoter may then result from competitive binding or from an abortive association between E2 and TFIID on overlapping sites. The interference between E2 and TFIID that we observed was not as drastic as the E2-dependent transcriptional repression of the $\mathrm{P}_{105}$ promoter of HPV-18 and was more efficient when an E2 protein truncated from the amino-terminal domain was used (data not shown). It is plausible that E2 will block more efficiently the binding of the more complex native TFIID factor isolated from nuclei than the purified TFIID gene product (Hoffmann et al. 1990; Peterson et al. 1990).

Competitive binding between E2 and a positive-acting transcription factor that can bind $\sim 20$ nucleotides downstream of the transcription start site of the BPV-1 P1 $\left(\mathrm{P}_{7185}\right)$ promoter has been described recently (Stenlund and Botchan 1990; Van de Pol and Howley 1990). In this study repression by E2 appears to be mediated by interference with a direct component of the initiation complex. Similar direct competition between TFIID and the engrailed homeo protein for binding to the Drosophila hsp70 and other TATA boxes was recently observed leading to the in vitro repression of these promoters, although the biological significance of this phenomenon remains unclear (Ohkuma et al. 1990).

In contrast to the observations with the original $\mathrm{P}_{105}$ derived oligonucleotide, when five nucleotides were inserted between the two DNA targets, E2 preferentially bound the same DNA molecule bound by TFIID, suggestive of a possible cooperativity in binding. As demonstrated by band-shift assays in the presence of anti-E2 antibodies, the complex containing both E2 and TFIID bound simultaneously on the same probe migrated in the gel-shift assay at the same position as the band observed with TFIID alone. The following section attempts to explain this apparent paradox. Although it is generally believed that the mobility of bands in such assays is only a function of the mass of bound proteins, experimental data contradict this fact. For example, the complex formed by the Jun/Fos heterodimer migrates faster than that formed by the Jun/Jun homodimer of a lower molecular weight (Hirai and Yaniv 1989). The shift obtained with TFIID is known to be anomalously large for a $30-\mathrm{kD}$ protein. It is practically identical to that observed with the SP1 transcription factor, which is $\sim 100 \mathrm{kD}$ (data not shown). In contrast, the shift observed with E2 is known to be small for a protein that is bound to DNA as a dimer of $\sim 100 \mathrm{kD}$. Because $\mathrm{E} 2$ is known to be sensitive to bacterial proteases (Dostatni et al. 1988) and although such degradation was not observed in yeast (Lambert et al. 1989a), it was still possible that the shift observed corresponds to the binding of a truncated version of E2 still able to bind DNA. This hypothesis could be excluded by the Western blot analyses done with polyclonal antibodies directed against the carboxy-terminal part of E2 containing the DNA-binding domain, which have shown that the preparation of E2 used in these experiments did not contain detectable polypeptides with molecular masses $<50 \mathrm{kD}$ (Fig. 8A). UV cross-linking experiments confirmed that the shift observed with E2 was due to binding of high molecular mass protein to the specific ACCGAAAACGGT sequence (data not shown). Finally, gel-shift experiments made in the presence of pronase indicate that the E2-specific band observed can be converted to a faster migrating band (data not shown).

We can propose several hypotheses to explain our findings. Gel-shift experiments are made in native gels, so the charge and native structure of proteins as well as structural modifications of the DNA or the proteins induced by DNA binding may affect the mobility of a particular complex. The E2 protein as well as TFIID are known to bend DNA (Moskaluk and Bastia 1988a; R. Roeder, pers. comm.). It is possible that simultaneous binding of E2 and TFIID can drastically affect the DNA structure leading to the unexpected migration of the ternary complex. On the other hand, because the precise stoichiometry of TFIID binding to DNA has not been established, it is theoretically possible that the original shift represents a complex in which two monomers of TFIID are bound and that specific binding of E2 to the probe can compete for the binding of one of these TFIID monomers. 
The choice between activation and repression depends on the location of the binding sites relative

to the transcription start site

This study describes the dual capacities of a viral protein to act either as a positive or a negative transcription factor in vitro. Similar properties have been described for the bacteriophage $\lambda$ repressor (Ptashne et al. 1980) and, to some extent, for the large T antigen of SV40 (Tjian 1981), although no evidence exists showing that SV40 T antigen has to bind the viral DNA to stimulate late transcription. In both cases, however, these proteins constitute strategic tools for the viruses to rapidly turn off transcription of some genes and stimulate expression of other ones. Furthermore, recent confirmation that E2 is indeed essential for BPV-1 DNA replication (Ustav and Stenlund 1991) and the possibility that formation of a complex between the E2 and E1 proteins is involved in DNA replication (Mohr et al. 1990) suggest that E2 binding next to the TATA box may repress early transcription and stimulate DNA replication at the same timeagain, a mechanism that recalls the duality of SV40 or polyoma virus $T$ antigen in the down-regulation of early transcription and the initiation of DNA replication (Tooze 1981). The in vitro transcription system described in this study clearly demonstrates that the same protein can function directly as both an activator and a repressor of transcription and provides a partial understanding of the mechanism by which this protein can have opposite activities. As in the case of bacteriophage $\lambda$ regulation, the position of the DNA-bound E2 protein relative to the AT-rich box appears to determine the mode of regulation, be it activation or repression of transcription. Finally, the repression of the HPV-18 $\mathrm{P}_{105}$ promoter by the full-length purified BPV-1 E2 protein in vitro established unambiguously that the presence of a functional trans-activation domain does not prevent E2 from repressing transcription of this promoter.

\section{Materials and methods}

Production and purification of BPV-1 E2 from yeast cells

The production of the $\mathrm{E} 2$ protein from yeast was as described in Lambert et al. (1989a). For large-scale production of E2, 2 liters of culture was prepared in SD medium (high phosphate conditions) at $30^{\circ} \mathrm{C}$. When the culture reached 0.4 units $\left(O_{600}\right)$, the cells were centrifuged, washed two times with sterile water, and grown for $12 \mathrm{hr}$ under induced conditions in 4 liters of lowphosphate synthetic medium (Tsapis and Hinnen 1984). Cells were harvested by centrifugation, and total proteins were extracted as described in Lambert et al. (1989a). After ammonium sulfate precipitation $(50 \%)$, the pellet was resuspended in buffer 0 (20 mM Tris (pH 8), 0.1 mM EDTA, $1 \mathrm{~mm}$ PMSF, $0.5 \mathrm{~mm}$ dithiotreitol, $0.5 \mu \mathrm{M}$ leupeptin, $0.1 \mu \mathrm{M}$ pepstatin, and $20 \%$ glycerol]. The presence of BPV-1 E2 in the extracts was determined by DNA binding monitored by gel-shift assays. The extracts were then diluted with buffer $\mathrm{H}[20 \mathrm{~mm}$ Tris $(\mathrm{pH} 8), 1 \mathrm{~mm}$ EDTA, $10 \mathrm{~mm} \mathrm{MgCl}_{2}, 1 \mathrm{~mm}$ PMSF, $1 \mathrm{~mm}$ dithiotreitol, and $20 \%$ glycerol] until the solution reached a salt concentration equivalent to $0.1 \mathrm{M} \mathrm{KCl}$ and applied to heparin ultrogel column. Proteins were eluted with linear gradient of $0.1-0.5 \mathrm{M} \mathrm{KCl}$ in buffer
H. Active fractions $(0.3-0.4 \mathrm{M} \mathrm{KCl})$ were precipitated by ammonium sulfate $(50 \%)$ and the pellet was diluted in buffer $\mathrm{H}$ with $1 \mathrm{mg}$ of poly[d(I-C)] and $0.05 \% \mathrm{NP}-40$ until the solution reached a salt concentration equivalent to $0.25 \mathrm{M} \mathrm{KCl}$. The extract was then loaded onto $1 \mathrm{ml}$ of an oligonucleotide-specific affinity column, prepared by coupling the double-stranded oligonucleotide containing the E2-binding site to a $\mathrm{CnBr}$-activated Sepharose CL-2B column (Kadonaga and Tjian 1986). Proteins were step eluted with buffer $\mathrm{H}$ containing $0.05 \%$ NP-40 and various concentrations of $\mathrm{KCl}$. The active fractions $(0.65-0.7 \mathrm{M} \mathrm{KCl})$ contained a major peptide that migrated at $\sim 50 \mathrm{kD}$ in SDSPAGE (Fig. 1), which is close to the reported molecular mass of the full-length BPV-1 E2 (Hubbert et al. 1988; McBride et al. 1988; Lambert et al. 1989a). Its concentration was estimated to be $\sim 50 \mathrm{ng} / \mu \mathrm{l}$. For in vitro transcription assays, the purified protein was dialyzed against buffer $\mathrm{H}$ (containing $0.5 \mu \mathrm{g} / \mu \mathrm{l}$ of BSA). Its DNA-binding activity was evaluated by gel-shift assays as corresponding to $\sim 45 \mathrm{U} / \mu \mathrm{l}$. One unit is defined as the quantity of protein needed to shift $1 \mathrm{ng}$ of labeled probe, in an excess of probe.

\section{Plasmid constructions}

The original plasmid pTK80(C2AT) that generated the different templates (Monaci et al. 1988) contains 80 nucleotides of the TK promoter in front of a 375-nucleotide synthetic sequence containing no $G$ residues (G-free cassette). This plasmid was modified by elongating the sequence of the TK promoter to nucleotide -109 relative to the cap site and adding a polylinker containing the unique $B g / I I, X h o I$, and $B a m H I$ restriction sites and gave rise to PTK109[375]. Various numbers of copies of a doublestranded oligonucleotide containing the E2-binding site (described in Lambert et al. 1989a) were inserted in the unique Xhol site of pTK109[375], giving rise to the plasmids pTK109: $1 \mathrm{mtf}[375]$, pTK109:2mtfs[375], and pTK109:6mtfs [375| containing, respectively, one, two, or six copies of the E2-binding sequence (Fig. 2). To provide template for an internal control, a plasmid containing a shorter G-less cassette driven by the same version of the TK promoter $(-109 /+5)$, was constructed with polymerase chain reaction (PCR) amplification as specific primers, the universal M13 sequencing-primer, and an oligonucleotide sharing a $3^{\prime}$ part complementary to the $\mathrm{C}_{2} \mathrm{AT}$ sequence and a divergent $5^{\prime}$ part containing the sequence of an $X \mathrm{maI}$ restriction site (Fig. 2). The size of the G-free cassette, downstream of the TK promoter in the plasmid, is 247 nucleotides [pTK109(247)].

Plasmids containing a G-free cassette under the transcriptional control of the regulatory region of HPV-18 are described in Figure 2. Briefly, a PCR fragment was generated, spanning the HPV-18 $\mathrm{P}_{105}$ promoter sequence from a unique Avall site at position 56 to the initiation site at position 105 and a shorter G-free sequence of 183 nucleotides with an $\mathrm{XmaI}$ site at its $3^{\prime}$ end. The entire regulatory region of HPV- 18 was reconstituted by ligation of this PCR fragment with the HPV-18 fragment from BamHI (position 6929) to AvalI (position 56) and inserted into the purified large BamHI/XmaI fragment of pTK80(C2AT). A mutated plasmid p18mut|C2AT][183] was constructed by the same method with a primer spanning the $P_{105}$ sequence, which contains two mutations in the E2-binding site at position 58 of the HPV-18 sequence, changing the wild-type sequence ACCGAAAACGGT to a mutated sequence ACCGAAAACCCT. The $\mathrm{p} 18^{\star}$ plasmid was constructed by insertion of a fragment containing the SV40 enhancer (72-bp repeats) in the unique AccI site at position 7767 of the HPV-18 genome.

The primers used to generate the different PCR fragments are schematically positioned along tpTK109[375] in Figure 2. The 
sequences of these primers are M13 universal primer $15^{\prime}$ GTAAAACGACGGCCAGT-3'), C2AT primer (5'-CCGGCCCCGGGTATGGAAGGAGAATATAATT-3'), HPV-18 primers lwild type: 5'-GTCGGGACCGAAAACGGTGTATATAAAAGATGTGAGAAACACACCACAATACTATTTCCTCCTATTATCTT-3'; and mut: 5'-GTCGGGACCGAAAACCCTGTATATAAAAGATGTGAGAAACACACCACAATACTATTTCCTCCTATTCT $\left.-3^{\prime}\right)$.

\section{In vitro transcription assays}

Assays were carried out in a volume of $20 \mu \mathrm{l}$ of $25 \mathrm{mM}$ HEPES, $50 \mathrm{mM} \mathrm{KCl}, 6 \mathrm{~mm} \mathrm{MgCl} 2,12.5 \%$ glycerol, $4 \mathrm{~mm}$ spermidine, 0.6 mM ATP and CTP, $0.1 \mathrm{~mm}$ 3-0-methyl-GTP, $5 \mu \mathrm{M}$ cold UTP, 7 $\mu \mathrm{Ci}$ of ${ }^{32}$-P-labeled UTP $(800 \mathrm{Ci} / \mathrm{mmole})$, and 30 units of RNasin. Rat liver nuclear extracts prepared as described by Gorski et al. (1986) were used as the source of general transcription factors. Transcription efficiency was optimized for each preparation of extract by varying the relative amount of DNA template and nuclear extract. Total DNA concentration was maintained constant in each assay with a carrier DNA (Blue-scribe plasmid|. Details of the concentrations of specific plasmids used in each experiment are given in the figure legends. Usually, varying amounts of purified E2 were first incubated with DNA for $5 \mathrm{~min}$ on ice before addition of the nuclear extract; controls were done with the same volume of dialysis buffer containing $0.5 \mu \mathrm{g} / \mu \mathrm{l}$ of BSA. Transcriptions were initiated by the addition of the nucleotides to the reactions and were carried out for $1 \mathrm{hr}$ at $30^{\circ} \mathrm{C}$. The reactions were stopped by the addition of $280 \mu \mathrm{l}$ of a solution containing $1 \%$ SDS, $0.25 \mathrm{M} \mathrm{NaCl}, 20 \mathrm{mM}$ Tris $(\mathrm{pH}$ 7.5), $5 \mathrm{~mm}$ EDTA, followed by a proteinase $\mathrm{K}$ digestion $(40 \mu \mathrm{g})$ for $30 \mathrm{~min}$ at $30^{\circ} \mathrm{C}$. The products of the in vitro transcription were on a $4 \%$ sequencing gel. Quantitation of the products of in vitro transcription was done by the scanning of short exposures of the autoradiograms with a Bio-Rad densitometer. Relative values of the ratios between the specific and the control transcription products were calculated for each assay and are given in the figure legends.

\section{DNA-binding assays}

Four different double-stranded oligonucleotides were used as specific probes in the gel-shift assays. Probe E2T contained the sequence of the HPV-18 $P_{105}$ promoter from position 57 to 85 flanked by $X$ hol cohesive sites at each end, and probe $\mathrm{E} 2-\mathrm{N}_{5}-\mathrm{T}$ is derived from E2T with a 5-nucleotide insertion between the E2-binding site and the TATA box of the $\mathrm{P}_{105}$ promoter. Finally, E2MT and E2TM are identical to E2T but contain, respectively, a double point mutation in the E2 DNA-binding site changing the wild-type sequence ACCGAAAACGGT to a mutated sequence ACCGAAAACCCT, or a double-point mutation in the TATA box changing the wild-type sequence TATAAAA to a mutated sequence CCTAAAA. The sequences of the oligonucleotides used as probe in the gel-shift assays are E2T (TCGAACCGAAAACGGTGTATATAAAAGA TGTGTCGATCGA); E2-N 5 -T(TCGAACCGAAAACGGTGATCCGTATATAAAAGATGTGTCGATCGA); E2MT (TCGAACCGAAAACCCTGTATATAAAAGATGTGTCGATCGA); $\overline{\text { and E2TM }}$ TCGAACCGAAAACGGTGTACCTAAAAGATGTGTCGATCGA). Binding reactions were carried out in a volume of $20 \mu \mathrm{l}$ in the presence of $12 \mathrm{~mm}$ HEPES $\{\mathrm{pH}$. 7.9\}, $10 \%$ glycerol, $0.5 \mathrm{~mm}$ EDTA, $5 \mathrm{~mm} \mathrm{MgCl}_{2}, 60 \mathrm{~mm} \mathrm{KCl}, 4 \mathrm{~mm}$ spermidine, $0.1 \% \mathrm{NP}$ 40 , and $500 \mathrm{ng} / \mu \mathrm{l}$ of bovine serum albumin in the presence of $600 \mathrm{ng}$ of poly[d(G-C)]. Binding incubations were performed first with $\mathrm{E} 2$ for $10 \mathrm{~min}$ on ice, followed by $30 \mathrm{~min}$ at $30^{\circ} \mathrm{C}$ after addition of TFIID, and then loaded on a low ionic strength $5 \%$ acrylamide (29: 1) gel containing $0.5 \times$ TBE.

\section{Antiserum and Western blot analysis}

The preimmune and immune sera were obtained from rabbits. The immune serum was raised by immunization with a fusion protein between Staphylococcus protein A and a portion of the E2 protein of BPV-1 extending from the KpnI restriction site (position 3460) to the carboxy-terminal end of the ORF. For immunoblotting, proteins were separated on $10 \%$ SDS-polyacrylamide gels and transferred to nitrocellulose membranes. The membranes were blocked for $30 \mathrm{~min}$ at room temperature with TBST [150 mM NaCl, $10 \mathrm{~mm}$ Tris- $\mathrm{HCl}(\mathrm{pH} 8), 0.05 \%$ Tween $20 \mid, 2 \%$ BSA, and $2 \%$ dried milk. The filters were then incubated for $1 \mathrm{hr}$ at room temperature with the unpurified anti-E2 anti-serum (or preimmune serum) diluted 200-fold in TBST containing $0.2 \%$ BSA, washed three times in TBST, incubated with an anti-rabbit IgG alkaline phosphatase-conjugate, and developed by the protocol supplied with the blotting detection kit (Promega).

\section{Acknowledgments}

This work was supported in part by a NATO grant for International Collaboration in Research to P.H. and M.Y., as well as grants from the Association pour la Recherche sur le Cancer, the Ligue Nationale Française contre le Cancer, the Fondation pour la Recherche Médicale, and the Institut National de la Santé et de la Recherche Médicale to M.Y. J.H. was supported by a SERC/NATO fellowship. We thank Ricardo Cortese for the gift of the pTK80(C2AT) plasmid. We are indebted to Frank Pugh and Robert Tjian for the gift of purified human TFIID, to Monika Lusky for the gift of nuclear extract from baculovirusinfected cells expressing E2, and to John Brady for the gift of and the help in preparation of HeLa whole-cell extracts. We thank Marta Blumenfeld, Silvia Cereghini, and Tanguy Chouard for advice in the preparation of liver extracts. We particularly appreciate constant support, critical discussions, and readings from Françoise Thierry, as well as communication of unpublished results.

The publication costs of this article were defrayed in part by payment of page charges. This article must therefore be hereby marked "advertisement" in accordance with 18 USC section 1734 solely to indicate this fact.

\section{References}

Androphy, E.J., D.R. Lowy, and J.T. Schiller. 1987. Bovine papillomavirus E2 trans-activating gene product binds to specific sites in papillomavirus DNA. Nature 325: 70-73.

Baker, C.C., W.C. Phelps, V. Lindgren, M.J. Braun, M.A. Gonda, and P.M. Howley. 1987. Structural and transcriptional analysis of human papillomavirus type 16 sequences in cervical carcinoma cell lines. J. Virol. 61: 962-971.

Bernard, B.A., C. Bailly, M.C. Lenoir, M. Darmon, F. Thierry, and M. Yaniv. 1989. The human papillomavirus type 18 (HPV18) E2 gene product is a repressor of the HPV18 regulatory region in human keratinocytes. I. Virol. 63: 43174324.

Choe, J., P. Vaillancourt, A. Stenlund, and M. Botchan. 1989. Bovine papillomavirus type 1 encodes two forms of a transcriptional repressor: Structural and functional analysis of new viral cDNAs. J. Virol. 63: 1741-1755.

Cole, S. and O. Danos. 1987. Nucleotide sequence and compar- 
ative analysis of the human papillomavirus type 18 genome. J. Mol. Biol. 193: 599-608.

Croston, G.E., L.A. Kerrigan, L.M. Lira, D.R. Marshak, and J.T. Kadonaga. 1991. Sequence-specific antirepression of histone Hl-mediated inhibition of basal RNA polymerase II transcription. Science 251: 643-649.

Dostatni, N., F. Thierry, and M. Yaniv. 1988. A dimer of BPV1 E2 protein containing a protease resistant core interacts with its DNA target. EMBO J. 7: 3807-3816.

Dostatni, N., I. Giri, R. Sousa, F. Thierry, and M. Yaniv. 1989. Mechanism of activation and repression of viral transcription by the E2 product of papillomaviruses. In Common mechanisms of transformation by small DNA tumor viruses (ed. Luis P. Villareal), pp. 165-180. American Society for Microbiology, Washington, D.C.

Garcia-Carranca, A., F. Thierry, and M. Yaniv. 1988. Interplay of viral and cellular proteins interaction along the long control region of human papillomavirus 18. \%. Virol. 62: 4321-4330.

Gauthier, J.M., N. Dostatni, M. Lusky, and M. Yaniv. 1991. Two DNA-bound E2 dimers are required for strong transcriptional activation and for cooperation with cellular factors in most cells. New Biologist 3: 498-509.

Giri, I. and M. Yaniv. 1988. Structural and mutational analysis of E2 trans-activating proteins of papillomaviruses reveals three distinct functional domains. EMBO J. 7: 2823-2829.

Giri I., O. Danos, F. Thierry, E. Georges, and M. Yaniv. 1985. Characterization of transcriptional control regions of the cottontail rabbit papillomavirus. Papillomavirus: Molecular and clinical aspects. UCLA Symp. Mol. Cell. Biol. 32: 379 390.

Gorski, K., M. Carneiro, and U. Schibler. 1986. Tissue-specific in vitro transcription from the mouse albumin promoter. Cell 47: 767-776.

Harrison, S.M., K.L. Gearing, S.Y. Kim, A.J. Kingsman, and S.M. Kingsman. 1987. Multiple cis-acting elements in the control region of bovine papillomavinus type 1(BPV-1). Nucleic Acids Res. 15: 10267-10284.

Hawley-Nelson, P., E.J. Androphy, D.R. Lowy, and J.T. Schiller. 1988. The specific DNA recognition sequence of the bovine papillomavirus E2 protein is an E2-dependent enhancer. EMBO I. 7: 525-531.

Hermonat, P.L., B.A. Spalholz, and P.M. Howley. 1988. The bovine papillomavirus type $1 \mathrm{P}_{2443}$ promoter is $\mathrm{E} 2$ transresponsive: Evidence for autoregulation. EMBO I. 9: 28152822.

Hirai, S.I. and M. Yaniv. 1989. Jun DNA-binding is modulated by mutations between the leucines or by direct interaction of fos with the TGACTCA sequence. New Biologist 1: 181191.

Hoffmann A., E. Sinn, T. Yamamoto, J. Wang, A. Roy, M. Horikoshi, and R. Roeder. 1990. Highly conserved core domain and unique $\mathrm{N}$ terminus with presumptive regulatory motifs in human TATA factor (TFIID). Nature 346: 387-390.

Hope, I.A., S. Mahadevan, and K. Struhl. 1988. Structural and functional characterization of the short acidic transcriptional activation region of yeast GCN4 protein. Nature 333: 635-640.

Hubbert, N.L., J.T. Schiller, D.R. Lowy, and E.J. Androphy. 1988. Bovine papillomavirus transformed cells contain multiple E2 proteins. Proc. Natl. Acad. Sci. 85: 5864-5868.

Kadonaga, J.T. and R. Tjian. 1986. Affinity purification of sequence specific DNA binding proteins. Proc. Natl. Acad. Sci. 83: $5889-5893$.

Lambert, P.F., B.A. Spalholz, and P.M. Howley. 1987. A transcriptional repressor encoded by BPVI shares a common carboxy terminal domain with the E2 transactivator. Cell
50: $69-78$.

Lambert, P.F., N. Dostatni, A.A. McBride, M. Yaniv, P.M. Howley, and B. Arcangioli. 1989a. Functional analysis of the papillomavirus E2 transactivator in Saccharomyces cerevisiae. Genes \& Dev 3: 38-48.

Lambert, P.F., N.L. Hubbert, P.M. Howley, and J.T. Schiller. $1989 \mathrm{~b}$. Genetic assignment of multiple E2 gene products in bovine papillomavirus-transformed cells. J. Virol. 63: 31513154.

Lambert, P.F., B.A. Monk, and P.M. Howley. 1990. Phenotypic analysis of bovine papillomavirus type $1 \mathrm{E} 2$ repressor mutants. J. Virol. 64: 950-954.

Levine, M. and J. Manley. 1989. Transcriptional repression of eukaryotic promoters. Cell 59: 405-408.

Lewin, B. 1990. Commitment and activation at Pol II promoters: A tail of protein-protein interaction. Cell 61: 11611164.

McBride, A.A., R. Schlegel, and P.M. Howley. 1988. The carboxy-terminal domain shared by the bovine papillomavirus E2 transactivator and repressor proteins contains specific DNA binding activity. EMBO J. 7: 533-539.

McBride, A.A., J.C. Byrne, and P.M. Howley. 1989a. E2 polypeptides encoded by bovine papillomavirus type 1 form dimers through the common carboxyl-terminal domain: Transactivation is mediated by the conserved amino-terminal domain. Proc. Natl. Acad. Sci. 86: 510-514.

McBride, A.A., B.A. Spalholz, P.F. Lambert, and P. Howley. $1989 \mathrm{~b}$. Functional domains of the papillomavirus E2 proteins. In Common mechanisms of transformation by small DNA tumor viruses. (ed. Luis P. Villareal), pp. 115-126. American Society for Microbiology, Washington, D.C.

Mitchell, P. and R. Tjian. 1989. Transcriptional regulation in mammalian cells by sequence-specific DNA binding proteins. Science 245: 371-378.

Mohr, I.J., R. Clark, E. Sun, E.J. Androphy, P. Macpherson, and M.R. Botchan. 1990. Targeting the El replication protein to the papillomavirus origin of replication by complex formation with the E2 transactivator. Science 250: 1694-1699.

Monaci, P., A. Nicosia, and R. Cortese. 1988. Two different liver-specific factors stimulate in vitro transcription from the human $\alpha 1$-antitrypsin promoter. EMBO I. 7: 2075-2087.

Morrissey, L.C., J. Barsoum, and E.J. Androphy. 1989. Transactivation by the bovine papillomavirus E2 protein in Saccharomyces cerevisiae. I. Virol. 63: 4422-4425.

Moskaluk, C. and D. Bastia. 1987. The E2 'gene' of bovine papillomavirus encodes an enhancer binding protein. Proc. Nat1. Acad. Sci. 84: 1215-1218.

1988a. DNA bending is induced in an enhancer by the DNA-binding domain of the bovine papillomavirus E2 protein. Proc. Natl. Acad. Sci. 85: 1826-1830.

1988b. Interaction of the bovine papillomavirus type 1 E2 transcriptional control protein with the viral enhancer: Purification of the DNA-binding domain and analysis of its contact points with DNA. J. Virol. 62: 1925-1931.

- 1989. The bovine papillomavirus type 1 transcriptional activator $\mathrm{E} 2$ protein binds to its DNA recognition sequence as a dimer. Virology 169: 236-238.

Münger, K., W.C. Phelps, and P.M. Howley. 1990. Human papillomavirus and neoplastic transformation. In The cellular and molecular biology of human carcinogenesis (ed. R.K. Boutwell and I.L. Riegel|, vol. 11, pp. 223-254. Academic Press.

Ohkuma, Y., M. Horikoshi, R.G. Roeder, and C. Desplan. 1990. Engrailed, a homeodomain protein, can repress in vitro transcription by competition with the TATA box-binding protein transcription factor IID. Proc. Natl. Acad. Sci. 89: 22892293. 
Peterson, M.G., N. Tanese, B.F. Pugh, and R. Tjian. 1990. Functional domains and upstream activation properties of cloned human TATA binding protein. Science 248: 1625-1630.

Ptashne, M. and A.A.F. Gann. 1990. Activators and targets. Nature 346: 329-331.

Ptashne, M., A. Jeffrey, A.D. Johnson, R. Maurer, B.J. Meyer, C.O. Pabo, T.M. Roberts, and R.T. Sauer. 1980. How the $\lambda$ repressor and Cro work. Cell 19: 1-11.

Renkawitz, R. 1990. Transcriptional repression in eukaryotes. Trends Genet. 6: 192-196.

Romanczuk, H., F. Thierry, and P.M. Howley. 1990. Mutational analysis of cis elements involved in E2 modulation of human papillomavitus type $16 \mathrm{P}_{97}$ and type $18 \mathrm{P}_{105}$ promoters. $J$. Virol. 64: 2849-2859.

Sawadogo, M. and R. Roeder. 1985. Factors involved in specific transcription by human RNA polymerase II: Analysis by a rapid and quantitative in vitro assay. Proc. Natl. Acad. Sci. 82: 4394-4398.

Schwarz, E., U.K. Freese, L. Gissmann, W. Mayer, B. Roggenbuck, A. Stremlau, and H. Zur Hausen. 1985. Structure and transcription of human papillomavirus sequences in cervical carcinoma cells. Nature 314: 111-114.

Sousa, R., N. Dostatni, and M. Yaniv. 1990. Control of papillomavirus gene expression. Biochim. Biophys. Acta 1032: 1937.

Spalholz, B.A., Y.C. Yang, and P.M. Howley. 1985. Transactivation of a bovine papilloma virus transcriptional regulatory element by the E2 gene product. Cell 42: 183-191.

Spalholz, B.A., P.F. Lambert, C.L. Yee, and P.M. Howley. 1987. Bovine papillomavirus transcriptional regulation: Localization of the $\mathbf{E} 2$ responsive elements of the long control region. J. Virol. 61: 2128-2137.

Spalholz, B.A., J.C. Byrne, and P.M. Howley. 1988. Evidence for cooperativity between E2 binding sites in the E2 transregulation of bovine papillomavirus type 1. I. Virol. 62: 31433150 .

Stanway, C.A., M.P. Sowden, L.E. Wilson, A.J. Kingsman, and S.M. Kingsman. 1989. Efficient activation of transcription in yeast by BPV-1 E2 protein. Nucleic Acids Res. 17: 21872197.

Stenlund, A. and M. Botchan. 1990. The E2 trans-activator can act as a repressor by interfering with a cellular transcription factor. Genes \& Dev. 4: 123-136.

Stenlund, A., G.L. Bream, and M. Botchan. 1987. A promoter with an internal regulatory domain is part of the origin of replication in BPV-1. Science 236: 1666-1671.

Struhl, K. 1989. Helix-turn-helix, zinc-finger, and leucine-zipper motifs for eukaryotic transcriptional regulatory proteins. Trends Biochem. Sci. 14: 137-140.

Thierry, F. and P.M. Howley. 1991. Functional analysis of E2mediated repression of the HPV-18 P105 promoter. New Biologist 3: 90-100.

Thierry, F. and M. Yaniv. 1987. The BPV1-E2 trans-acting protein can be either an activator or a repressor of the HPV18 regulatory region. $E M B O$ /. 6: 3391-3397.

Thierry, F., N. Dostatni, F. Arnos, and M. Yaniv. 1990. Cooperative activation of transcription by bovine papillomavirus type 1 E2 can occur over a large distance. Mol. Cell. Biol. 10: $4431-4437$.

Tiian, R. 1981. T antigen binding and the control of SV40 gene expression. Cell $26: 1-2$.

Tooze, J. 1981. DNA tumor viruses: Molecular biology of tumor viruses, 2nd ed., Cold Spring Harbor Laboratory, Cold Spring Harbor, New York.

Tsapis, R. and A. Hinnen. 1984. A deletion that includes the signal peptidase cleavage site impairs processing, glycosyla- tion, and secretion of cell surface yeast acid phosphatase. Mol. Cell. Biol. 4: 2668-2675.

Ustav, M. and A. Stenlund. 1991. Transient replication of BPV-1 requires two viral polypeptides encoded by the $\mathrm{E} 1$ and $\mathrm{E} 2$ open reading frames. EMBO $/$. 10: 449-457.

Van de Pol, S.B. and P.M. Howley. 1990. A bovine papillomavirus constitutive enhancer is negatively regulated by the E2 repressor through competitive binding for a cellular factor. $J$. Virol. 64: 5420-5429.

Workman, I.L., I.C.A. Taylor, and R.E. Kingston. 1991. Activation domain of stably bound Gal4 derivatives alleviate repression of promoters by nucleosomes. Cell 64: 533-544. 


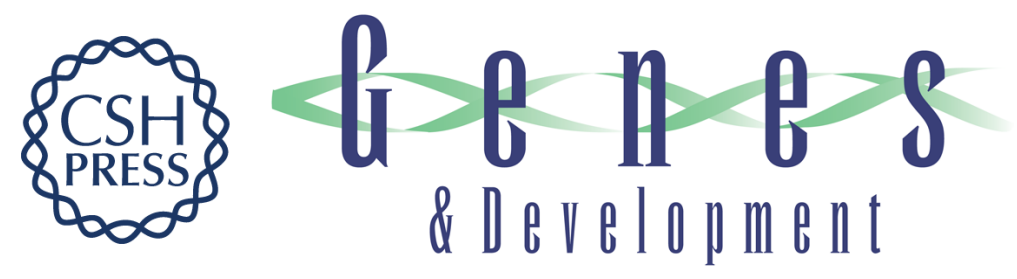

\section{The functional BPV-1 E2 trans-activating protein can act as a repressor by preventing formation of the initiation complex.}

N Dostatni, P F Lambert, R Sousa, et al.

Genes Dev. 1991, 5:

Access the most recent version at doi:10.1101/gad.5.9.1657

References This article cites 60 articles, 26 of which can be accessed free at: http://genesdev.cshlp.org/content/5/9/1657.full.htmI\#ref-list-1

License

Email Alerting

Receive free email alerts when new articles cite this article - sign up in the box at the top Service right corner of the article or click here.

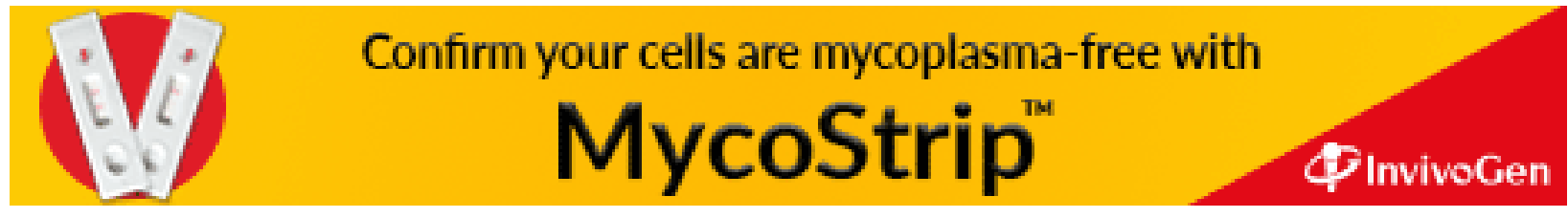

